\title{
Exploration and Practice of Curriculum Ideological and Political Construction of Operational Research
}

\author{
Lan Shujuan ${ }^{1, \mathrm{a}}$ \\ ${ }^{1}$ Department of Management Science and Engineering, Beijing Institute of Technology, Zhuhai, Tangjia Bay, Zhuhai, \\ Guangdong, China \\ a orange8401@163.com
}

\begin{abstract}
As an important professional basic course of all majors in business school, its teaching quality and ideological and political construction directly affect the quality of talents and students' quality and ability. Based on the current teaching process of Operations Research in business school, this paper explores how to integrate ideological and political education elements into the existing teaching curriculum system and apply them to teaching practice; Combined with the practical cases of teaching units, this paper analyzes and summarizes the ideological and political instructional design of Operations Research, in order to provide reference and suggestions for the ideological and political construction of relevant courses.
\end{abstract}

Keywords: Operational Research, Curriculum of political and ideological education, instructional design

\section{《运筹学》课程思政建设探索与实践}

\section{兰淑娟 1, a}

\author{
'北京理工大学珠海学院, 唐家湾, 珠海, 广东, 中国 \\ orange8401@163.com
}

\section{摘要}

运筹学作为商学院各专业的一门重要专业基础课, 它的教学质量和思政建设直接影响着学院培养的人才质量和 学生素质与能力。本文主要基于商学院运筹学目前的教学过程, 探索如何将思政教育元素融入现有教学课程体 系, 并用于教学实践; 并结合教学单元实践案例, 对运筹学课程思政教学设计进行了分析与总结, 旨在为相关 课程思政建设提供参考建议。

关键词: 运筹学, 课程思政, 教学设计

\section{1. 前言}

运筹学是一门与自然科学、社会科学、技术科学 交叉性较强的科学; 是平行于数学、经济学等学科的 一级学科, 又被称为管理科学, 应用于军事、经济、 管理等各个领域 ${ }^{[1]}$ 。该课程被设立为商学院各专业基 础课程, 主要培养学生发现问题, 建立模型, 定量分 析解决问题的能力, 并为后续专业课程的学习奠定基 础。习近平总书记指出高校立身之本在于立德树人, 要全面贯彻党的教育方针, 解决好培养什么人、怎样 培养人、为谁培养人这个根本问题 ${ }^{[1-2]}$ 。基于以上根 本问题, 教师在授业解惑的同时, 更要注重 “传道”,
通过课程思政教育, 全面塑造学生正确的世界观、价 值观、人生观。

\section{2. 课程思政建设思路}

根据商学院各专业及课程特点, 可以选取多角度 切入，探索专业课程教育与思政的有机融合。

\section{1. 挖掘 “课程思政” 点}

调整教学内容, 优化教学项目, 找到解决问题的 重点和难点, 结合教学项目和相关问题深挖 “课程思 政”要素。 


\section{2. 编制 “课程思政” 教学设计}

进行专业知识与思想政治点的融合，进行资源的 重新组合, 编制 “课程思政” 教学设计等, 收集实际 运行和思政教育的各种案例及音视频资料, 形成系统 完整的课程教学资料。

\section{3. 完善优化思政元素}

经过一轮教学后, 通过各方面的反馈, 完善和优 化教学模式，对《运筹学》课程融入的思想政治元素 进行优化和完善, 对课程的思想政治教学进行改进和 提高, 形成适用于课程教学内容和教学规律的、有助 于加深学生对知识点掌握的、润物细无声的思想嵌入 方式，提炼改革成果。

\section{3. 课程思政教学设计}

课程思政教学按照从全局到部分进行设计, 以教 育部《高等学校课程思政建设指导纲要》为指导, 明 确政策目标和任务, 结合课程实际, 将课程内容和思 政元素有机结合 ${ }^{\left[{ }^{[3]}\right.}$ 。

课程教学大纲是教师进行课程教学工作的指南, 也体现了课程的总体设计, 首先对教学大纲进行修订,
提炼各章节的思政融入点，突出价值观塑造部分，介 绍中国在运筹思想和运筹学发展中的成就, 培养家国 情怀，激发爱国热情，同时强调学生分析解决问题的 优化思维习惯。

教学设计采用以问题为导向, 在学习理论知识之 前提出生活中或实践生产中存在的问题, 让同学们思 考, 并运用现有知识体系尝试进行解决、讨论当前解 决方案的不足或问题, 在学习理论知识之后进行重新 建模, 并求解模型, 实现 “五位一体” 建构式教学, 将问题思考、共同研讨、知识获取、实验实践、汇报 交流五种方式结合在一起，展开课程教学。

通常在介绍一个新的分支内容时, 会采用新课案 例导入 (创设问题情境)、讨论交流（探索新知、思 政融入) 、知识讲解 (提供必要条件、思政融入) 、反 馈练习（巩固强化）、总结归纳（反思回顾，思政融 入)。

\section{4. 课程思政实施方案}

按照课程大纲设计的培养目标, 结合教学内容所 涉及到的运筹学各分支, 制定课程实施方案。围绕课 程建设全过程, 分解知识点, 融合思政元素, 实现思 政目的，如表 1 所示。

\section{表 1 《运筹学》课程思政实施方案}

\begin{tabular}{|c|c|c|c|c|}
\hline 序号 & 教学单元 & 实施方法 & 思政要素 & 预期成效 \\
\hline 1 & $\begin{array}{l}\text { 运筹学 } \\
\text { 概论 }\end{array}$ & $\begin{array}{l}\text { 介绍中国古代运筹思想的应用 (如田忌赛马, 孙子兵 } \\
\text { 法, 丁谓挖渠修复皇宫) } \\
\text { 运筹学学科的产生 } \\
\text { (二战对德作战产生的学科) } \\
\text { 运筹学在中国的发展 (融入钱学森、华罗庚等科学家 } \\
\text { 对运筹学的推动作用) }\end{array}$ & $\begin{array}{l}\text { 爱国情怀 } \\
\text { 使命感 } \\
\text { 民族自信 } \\
\text { 奋发有为 }\end{array}$ & $\begin{array}{l}\text { 坚定文化自信 } \\
\text { 弘扬爱国精神 }\end{array}$ \\
\hline 2 & $\begin{array}{l}\text { 线性规划建 } \\
\text { 模引入 }\end{array}$ & $\begin{array}{l}\text { 通过相对简单的线性规划问题进行数学模型构建, 并 } \\
\text { 分析线性规划模型的特点 }\end{array}$ & $\begin{array}{l}\text { 分析问题从简 } \\
\text { 单到复杂的思 } \\
\text { 维方式 }\end{array}$ & $\begin{array}{l}\text { 让学生理解分析问题 } \\
\text { 逻辑的共通性 } \\
\text { 克服畏难情绪 }\end{array}$ \\
\hline 3 & $\begin{array}{l}\text { 线性规划的 } \\
\text { 求解 }\end{array}$ & $\begin{array}{l}\text { 讲解单纯形法的思想和算法流程, 以及算法中体现的 } \\
\text { 循迭代迭代思想和辩证矛盾思想 }\end{array}$ & $\begin{array}{l}\text { 循环迭代思想 } \\
\text { 矛盾论思想 }\end{array}$ & $\begin{array}{l}\text { 培养学生思考问题的 } \\
\text { 逻辑性和整体性 }\end{array}$ \\
\hline 4 & $\begin{array}{c}\text { 线性规划的 } \\
\text { 应用 }\end{array}$ & $\begin{array}{l}\text { 讲解各种线性规划典型应用及建模 (如人力资源分配 } \\
\text { 问题、配料问题、套裁下料问题、投资问题、生产计 } \\
\text { 划问题等) }\end{array}$ & $\begin{array}{l}\text { 节约资源 } \\
\text { 提高经济效益 } \\
\text { 科教兴国 }\end{array}$ & $\begin{array}{l}\text { 培养学生的优化思 } \\
\text { 维; 树立社会责任意 } \\
\text { 识和使命感 }\end{array}$ \\
\hline 5 & $\begin{array}{l}\text { 线性规划对 } \\
\text { 偶问题 }\end{array}$ & $\begin{array}{l}\text { 基于一个实际的线性规划问题, 从不同角度思考和运 } \\
\text { 作提出新的对偶规划, 分析两个规划之间的联系与对 } \\
\text { 偶性 }\end{array}$ & 辩证统一思想 & $\begin{array}{l}\text { 树立正确的世界观和 } \\
\text { 方法论 }\end{array}$ \\
\hline
\end{tabular}




\begin{tabular}{|c|c|c|c|c|}
\hline 6 & $\begin{array}{l}\text { 灵敏度 } \\
\text { 分析 }\end{array}$ & $\begin{array}{l}\text { 通过改变线性规划问题的资源条件、外部环境或生产 } \\
\text { 工艺重新分析问题的最佳方案和结果, 并结合经济学 } \\
\text { 中的机会成本进行分析 }\end{array}$ & $\begin{array}{l}\text { 发展观点的方 } \\
\text { 法论 }\end{array}$ & $\begin{array}{l}\text { 学习用发展变化的眼 } \\
\text { 光看待问题思考问题 }\end{array}$ \\
\hline 7 & 运输问题 & $\begin{array}{l}\text { 通过特殊的线性规划问题引入运输问题, 并介绍针对 } \\
\text { 这种特殊线性规划问题的求解方法一一表上作业法, } \\
\text { 以及各种不平衡问题的转换; 通过认识运输问题的本 } \\
\text { 质特征, 进行建模应用, 如相应的生产存储问题转化 } \\
\text { 为运输问题 }\end{array}$ & $\begin{array}{l}\text { 分析问题从一 } \\
\text { 般到特殊的思 } \\
\text { 维方式 } \\
\text { 提高经济效益 } \\
\text { 科教兴国 }\end{array}$ & $\begin{array}{l}\text { 理解事物发展的普遍 } \\
\text { 规律和特殊表现, 培 } \\
\text { 育学生社会主义核心 } \\
\text { 价值观中和谐的理念 }\end{array}$ \\
\hline 8 & $\begin{array}{l}\text { 动态规划基 } \\
\text { 本概念及应 } \\
\text { 用 }\end{array}$ & $\begin{array}{l}\text { 通过简单的引例介绍动态规划的基本概念和思想, 把 } \\
\text { 一个较大的问题分解成若干阶段的小问题, 从后往 } \\
\text { 前、从确定到不确定、倒推式地求解问题, 并通过讲 } \\
\text { 解动态规划的典型应用让学生体会其中所蕴含的递 } \\
\text { 归思想 }\end{array}$ & $\begin{array}{l}\text { 递归思想 } \\
\text { 逆向思维 } \\
\text { 提高经济效益 } \\
\text { 科教兴国 }\end{array}$ & $\begin{array}{l}\text { 培养学生辩证、阶段 } \\
\text { 性地动态分析问题并 } \\
\text { 采用递归思想逆序求 } \\
\text { 解问题 }\end{array}$ \\
\hline 9 & 目标规划 & $\begin{array}{l}\text { 面对问题的多个目标要分清轻重缓急, 把我事物主要 } \\
\text { 方面, 避免陷入均衡论而无方案 }\end{array}$ & $\begin{array}{l}\text { 分清主次、循序 } \\
\text { 渐进的思维方 } \\
\text { 式 }\end{array}$ & $\begin{array}{l}\text { 培养学生做事情善于 } \\
\text { 抓住矛盾主要方面的 } \\
\text { 思维和能力 }\end{array}$ \\
\hline 10 & $\begin{array}{c}\text { 图与网络分 } \\
\quad \text { 析 }\end{array}$ & $\begin{array}{l}\text { 介绍图与网络的基本概念, 最小生成树问题、最短路 } \\
\text { 问题、最大流问题、最小费用最大流问题、中国邮递 } \\
\text { 员问题, 并通过简单实例让学生体会对事物间的联系 } \\
\text { 如能采用图与网络的抽象可以大大简化问题 }\end{array}$ & $\begin{array}{l}\text { 普遍联系原理 } \\
\text { 节约资源 } \\
\text { 提高经济效益 } \\
\text { 科教兴国 }\end{array}$ & $\begin{array}{l}\text { 体会普遍联系原理, } \\
\text { 锻炼学生对具体问题 } \\
\text { 建立网络关系并进行 } \\
\text { 抽象概括的能力 }\end{array}$ \\
\hline 11 & 整数规划 & $\begin{array}{l}\text { 从一般线性规划到整数规划的引入, 主要介绍整数规 } \\
\text { 划的典型应用及建模技巧, 特别是 } 0-1 \text { 变量在建模中 } \\
\text { 的指示作用 }\end{array}$ & $\begin{array}{l}\text { 分析问题从一 } \\
\text { 般到特殊的思 } \\
\text { 维方式 } \\
\text { 提高经济效益 }\end{array}$ & $\begin{array}{l}\text { 让学生深刻理解理论 } \\
\text { 来源于实践, 积极利 } \\
\text { 用所学理论指导实践 }\end{array}$ \\
\hline 12 & 决策论 & $\begin{array}{l}\text { 介绍不确定性问题的决策准则及风险性问题的决策 } \\
\text { 准则, 并通过实例体会不同的决策者有不同的风格和 } \\
\text { 偏好, 体会科学发展观以人为本的核心 }{ }^{[4]}\end{array}$ & $\begin{array}{l}\text { 以人为本 } \\
\text { 管理科学性和 } \\
\text { 艺术性的统一 }\end{array}$ & $\begin{array}{l}\text { 强调面对不确定性时 } \\
\text { 人的重要性, 体会科 } \\
\text { 学发展观以人为本的 } \\
\text { 核心 }\end{array}$ \\
\hline
\end{tabular}

\section{5. 课程思政教学设计实例展示}

为了更好地体现课程中思政元素的融入，下面以 线性规划建模知识单元为例来进行课程思政教学设 计的展示。

\section{1 线性规划建模知识单元教学目标}

知识培养方面: 线性规划建模基本概念、步骤及 应用

能力培养方面: 对现实问题进行抽象，能从中发 现问题、分析问题

思想培养方面：对复杂问题进行建模的思想

\section{2 教学方法}

针对商学院学生特点, 运筹学课程的教学也要积 极创新教学方法, 教师通过总结以往的教学经验, 整 合现代化具有创新性的教学手段, 为学生们构建良好
的课程学习意境, 例如, 教师可以积极利用启发教学 法、项目教学法、合作教学法及情境教学法等, 创新 运筹学课程教学的模式和思路 ${ }^{[5]}$ 。通过多种教学方法 进行新课案例导入 (创设情境) 、在相关背景下进行 知识讲解 (提供条件)、有了基本知识储备后提供问 题供学生讨论交流（探索新知, 思政融入)、及时反 馈练习 (巩固强化)、最后进行总结归纳 (反思回顾, 思政融入)。

\section{3 教学设计}

简单问题导入: [鸡兔同笼问题]今有雉（鸡）兔 同笼, 上有三十五头, 下有九十四足。问雉兔各几何。 解决办法: 设立方程组, 引出建模的本质。

加大问题难度：逐步分析、讲解、建模。在这里 进行思政要素的融入: 体会问题从简单到复杂的共性 和个性, 分析相关问题底层逻辑的共通性, 克服畏难 情绪。

知识总结: 线性规划建模的两个特点, 线性规划 
模型的三个要素, 线性规划建模的四个步骤。

课堂建模练习。

知识扩展: 通过例题和练习题进一步引出线性规 划模型的一般形式。(思政要素融入: 用从特殊到普 遍的思想去认识世界。）

探索新知, 引导学生讨论分析实际更复杂的应用 问题，如: 人力资源分配问题、生产计划问题、套裁 下料问题、合理配料问题、投资分配问题等。各个应 用问题都可以进行相应思政点的融入: 如套裁下料问 题, 首先介绍当前在工程管理中一些粗放式管理的做 法, 然后引导学生思考有无更好的方案可以节约原材 料, 进而通过一种有逻辑的顺序将所有可选方案列出, 并采用线性规划建模, 配合教学软件计算结果, 看到 科学管理优化带来的实际效益, 从而内化学生的学习 动力，报效祖国服务社会。

\section{6. 结语}

通过深挖运筹学课程内容的思政元素, 对课程模 块进行系统地梳理, 精心设计思政的内容和形式, 完 成课程模块与思政内容有机深入融合, “润物无声” 地进行价值引领和思政教育。同时 “课程思政” 让运 筹学课程更有人情味, 更贴近日常学习、生活和工作, 也让学生更有收获 ${ }^{[6]}$ 。

运筹学所包含的各个分支在许多领域都得到了 非常广泛的应用和实践, 例如物流仓储、金融工程以 及交通管理等领域都离不开运筹学的支持 ${ }^{[7]}$ 。总的来 说, 通过应用问题或实例的引入以及模型求解思路的 讲解, 一方面让学生提升民族自信、并充分认识到运 筹学在经济管理领域起到的实际作用, 激发学生学习 专业知识的动力, 增强社会责任感; 另一方面也培养 学生看待问题的优化思维和优化习惯, 可以在将来的 学习生活和工作中更加积极有效地面对问题、解决问 题，更好地报效祖国、服务社会。

\section{项目基金}

本文为广东省本科高校高等教育教学改革项目
《基于智慧教育技术的专业认知体系构建研究与实 践》(2017JXGG654) 阶段性成果之一。

\section{REFERENCES}

[1] Li Xiaojie. (2018) Research on Teaching Design of Operations Research Course Based on Problem Oriented Teaching. J. Journal of Higher Education, 04: 50-58.

[2] Huang Yan. (2020) On the Characteristics of Policy Development of Ideological and Political Theory Course in Colleges and Uuniversities in the Past 70 Years Since the Founding of New China. J. University Education Science, 03: 75-82.

[3] Huang Yan. (2021) On the development process and experience of collaborative education mechanism of Ideological and Political Education in Colleges and Universities in New China. J. New Silk Road Horizon, 05: 115-118.

[4] Wang Ying, Shao Guifang, Tao Jiping, Sun Huaiqing. (2021) Design and Exploration of Ideological and Political Education in Operations Research Course. J. Journal of Higher Education, 16: 172-176.

[5] Zhang Sheng, Li Yunyi. (2020) Practice of Operations Research Curriculum Reform Under the Background of New Business. J. Test Questions and Research, 34: 30-32.

[6] Song ZuoLin, Sun Hui. (2021) Practical Path and Strategy of Ideological and Political Integration Teaching in Operations Research Course. J. Logistics Technology, 08: 157-160.

[7] Tian Junfang, Zhong Shiquan, Jia Ning, Ling Shuai. (2021) Exploration and Practice of Ideological and Political Construction of Operations Research Course. J. China Journal of Multimedia \& Network Teaching, 09: 227-229. 